\title{
Sistema de informação em gestão social
}

\author{
MARIANGELA BELFIORE WANDERLEY
}

$\mathrm{E}$ SSE SISTEMA tem origem em pesquisa iniciada em 1996 e realizada em parceria entre o IEE/PUC-SP e a Secretaria de Cidadania e Ação Social da Prefeitura Municipal de Santo André, na perspectiva da articulação de programas, projetos e ações no contexto da gestão social municipal. Vivíamos, à época, as primeiras experiências municipais de implementação de programas de transferência de renda, mais conhecidos como programas de renda mínima, que têm como público-alvo famílias vulnerabilizadas.

Daquela primeira experiência até hoje, percorremos uma longa trajetória que nos permitiu aprofundar, testar e aprimorar nosso trabalho, fundamentado em referenciais teórico-metodológicos eleitos pela equipe e validados na intervenção direta na realidade social. Várias outras parcerias foram e estão sendo realizadas, o que nos permite constante avaliação e aprimoramento.

\section{Marcos conceituais do sistema}

Partimos de uma longa discussão sobre os conceitos de pobreza e desigualdades sociais, e também de exclusão e inclusão sociais, dada a centralidade dessas temáticas entendidas como manifestações de uma sociabilidade própria das sociedades capitalistas.

Entendemos que a pobreza e a exclusão social configuram-se como indicadores de um lugar social, de uma condição de classe, expressando relações vigentes na sociedade. São produtos dessas relações, produzindo e reproduzindo a desigualdade, nos planos social, político, econômico, definindo para os pobres um lugar na sociedade. Essa é uma questão social recorrente que perdura desde o período da colonização no continente latino-americano. Trata-se, pois, de um processo de empobrecimento histórico e social, dado por determinantes econômicos, políticos e culturais, que tende a ser reproduzido mediante mecanismos que o reforçam e o expandem.

A globalização financeira, cujas refrações tomam configurações específicas em cada país, está igualmente presente em nosso país, alimentando a generalização das relações mercantis para as várias dimensões da vida social. A relação Estado e sociedade é também atingida, reconfigurando-se e reconfigurando relações sociais. A regressão dos direitos sociais é um resultado desse movimento, que também ecoa nas atuais características das políticas públicas. A pobreza é, pois, produzida e reproduzida no seio dessas relações sociais, e os pobres apresentam-se destituídos de poder, trabalho e informação, para além dos indicadores clássicos de renda. 
A mensuração da pobreza, quanto à renda, é elemento indispensável para a elaboração de diagnósticos, mas está longe de esgotar a análise dos fenômenos nela contidos. Seu inerente caráter multidimensional torna indispensável a utilização de uma grade analítica que dê conta das inter-relações existentes.

Considerando-se que a maior parte da população brasileira vive em áreas urbanas e que nossa atuação tem se concentrado em regiões metropolitanas brasileiras, aprofundamos, ainda, nossos estudos sobre a pobreza urbana e suas conseqüências.

Na sociedade brasileira, os efeitos da pobreza são amplificados pela enorme distância entre os grupos sociais cravada pelas desigualdades sociais. Relatórios de diferentes organismos internacionais (BID, PNUD, por exemplo) indicam o Brasil como um dos países mais desiguais do planeta.

É nesse contexto que vimos emergir o amplo debate em torno da noção da exclusão/inclusão social. São noções polissêmicas e, portanto, englobando situações diversas e diferenciadas, daí a dificuldade de sua utilização como categorias analíticas. No entanto, apesar da polêmica que suscitam, possibilitam ultrapassar a discussão da carência e da renda precária, do não-atendimento das necessidades básicas, transitando para a reflexão sobre a eqüidade social, da emancipação e do pertencimento (Lavinas, 2003, p.2). Numa sociedade como a brasileira, em que as desigualdades sociais são imensas, a questão da exclusão/inclusão social se torna referência no debate das políticas públicas.

Quando desenvolvemos a parceria com a Prefeitura do Município de São Paulo (2002-2003), para a gestão do Programa Fortalecendo a Família/Renda Cidadã, entendemos ser fundamental a utilização de instrumentos territorializados de análise da realidade local. A então Secretaria de Assistência Social havia construído o Mapa da Vulnerabilidade Social do Município de São Paulo. ${ }^{1}$ A gestão da política de assistência social na cidade de São Paulo "propunha tratar a cidade e seu território como chão da política pública, permitindo perceber o território como mais um instrumento do social” (Koga, 2004, p.56).

Realidade complexa, o território traz elementos que permitem dar à questão social uma perspectiva de totalidade, pois, para além das condições objetivas que oferece, ou não, para os que nele habitam, como redes de serviços públicos, serviços privados, redes comunitárias etc., incorporar a dimensão territorial significa, também, considerar as dimensões subjetivas que decorrem das relações que os sujeitos estabelecem com seu território e que se manifestam em desejos, sonhos, sofrimentos etc. e nas redes de sociabilidade que constroem. O território contém certamente um componente geográfico, físico, concreto. Porém, é também uma construção sócio-histórica cujo significado lhe é atribuído por aqueles que nele vivem.

A vertente territorial permitia dimensionar a perspectiva particular-coletiva das famílias que constituem o público-alvo de programas sociais. Assim, o Sistema de Informação em Gestão Social (SIGS), ao incorporar a dimensão territorial, 
passou a gerar análises territorializadas que possibilitam a construção de mapas temáticos, de acordo com o desenho do programa monitorado.

As políticas públicas, portanto, têm necessariamente que considerar as particularidades de cada localidade, de cada território, especialmente em contextos de grandes desigualdades sociais.

A concepção de pobreza sustentada pela equipe e a situação específica das famílias envolvidas em programas sociais levaram-nos a eleger uma outra noção: a de necessidades humanas. Chegamos, assim, ao conceito de Autonomia.

Na tentativa de reelaborar a definição tradicional de "necessidades básicas", tal como veiculada na década de $1970^{2}$ pelas grandes organizações internacionais engajadas no combate à pobreza, Doyal \& Gough (1991) apontam que a universalidade e a objetividade do conceito residem na compreensão de que, se não forem satisfeitas, as carências podem causar sérios danos ao ser humano, comprometendo sua trajetória de vida. Daí caracterizar "necessidades básicas" como todo pré-requisito de cunho universalista indispensável à participação dos indivíduos no desenrolar da sua própria existência.

Para eles, as necessidades básicas - saúde e autonomia - "não são um fim em si mesmas, mas precondições para se alcançar objetivos universais de participação social". Sem elas, não há como se assegurar uma participação social conseqüente, em que possam ser processadas escolhas e atingidos objetivos ao longo da vida. Ainda segundo os autores, as políticas sociais, mais do que serem o instrumento adequado para suprir essas necessidades, são um dever moral que deve presidir um sistema de proteção social público e universal.

A saúde física é definida como "necessidade básica, porque sem a provisão devida para satisfazê-la os homens estarão impedidos inclusive de viver"; e autonomia básica como "a capacidade do indivíduo de eleger objetivos e crenças, de valorá-los com discernimento e de pô-los em prática sem opressões [...] Ser autônomo, nesse sentido, consiste em possuir capacidade de eleger opções informadas sobre o que se tem que fazer e de como levá-lo a cabo".

São descritas, também, "quatro precondições societais que estão relacionadas às dimensões da vida humana, para garantir e aperfeiçoar o enfrentamento efetivo das necessidades básicas: produção, reprodução, transmissão cultural e sistemas de autoridade".

Por fim, os autores preconizam que, apesar de as necessidades básicas serem comuns a todos, são sócio-históricas. Assim, não implicam uniformidade na sua satisfação e devem ser contextualizadas no tempo e no espaço socioeconômico, cultural etc. de cada realidade específica. Indicam, assim, onze variáveis (satisfiers) de satisfação das necessidades básicas humanas capazes de "melhorar as condições de vida e de cidadania das pessoas". Nove características são gerais - aplicam-se a todas as pessoas. Uma característica aplica-se às crianças e outra às mulheres, quais sejam:

\section{Alimentação nutritiva e água potável.}


2. Habitação adequada: garantia de abrigo suficiente, existência de saneamento, ausência de superlotação residencial.

3. Ambiente de trabalho desprovido de riscos.

4. Ambiente físico saudável.

5. Cuidados de saúde apropriados.

6. Proteção à infância.

7. Relações primárias significativas.

8. Segurança física.

9. Segurança econômica.

10. Educação apropriada.

11. Segurança no planejamento familiar, na gestação e no parto.

É importante ressaltar que as diferentes concepções sobre necessidades humanas têm implicações diretas na eleição de políticas voltadas à satisfação delas. Decorre daí o reconhecimento ou não da existência de necessidades objetivas e universais, e, portanto, da pertinência ou não de políticas públicas.

Amartya Sen $(2000)^{3}$ veio complementar o arcabouço teórico por nós utilizado com a noção de liberdade como fundamental para o desenvolvimento pleno do homem. Para o autor indiano, superar privação, destituição e opressão é parte central do processo de desenvolvimento. Para tanto, é preciso reconhecer o papel das diferentes formas de liberdades no combate a esses males e a condição de agente dos indivíduos para lidar com as privações. Para Sen, o crescimento econômico "não pode ser considerado um fim em si mesmo. O desenvolvimento tem de estar relacionado, sobretudo, com a melhoria de vida que levamos e das liberdades que desfrutamos" (ibidem, p.29). Dessa forma, a expansão da liberdade é vista, pelo autor, como o principal fim e o principal meio de desenvolvimento: "O desenvolvimento consiste na eliminação de privações de liberdade que limitam as escolhas e as oportunidades das pessoas de exercer ponderadamente sua condição de agente".

Um indivíduo autônomo age livremente de acordo com um plano próprio, de forma análoga a que um governo administra seu território e estabelece suas políticas. No entanto, como destaca Amartya Sen (2000, p.10) o papel de agente dos indivíduos é restrito e limitado pelas oportunidades sociais, políticas e econômicas presentes na sociedade: "É imprescindível o reconhecimento simultâneo da centralidade individual e da força das influências sociais sobre o grau e o alcance da liberdade individual. Para combater os problemas que enfrentamos, temos de considerar a liberdade individual um comprometimento social".

A visão de Amartya Sen (1992) corrobora a compreensão de que, tão importante quanto ter suas necessidades básicas atendidas, é dispor de condições meios para funcionar (functionnings ${ }^{4}$ ) e um conjunto de habilidades (capability set) - que permitam obter a satisfação de tais necessidades. Partindo desse pres- 
suposto, Sen contesta a abordagem da insuficiência de renda (consumada na adoção de linhas de pobreza), preferindo a ela a da inadequação, já que o montante ou patamar em questão vai forçosamente variar em razão das características pessoais e de outras circunstâncias tais como o ciclo de vida ou a conjuntura econômica etc. Em vez de se deter sobre o orçamento monetário disponível, Sen valoriza o conjunto de habilidades e capacidades ao alcance de cada indivíduo, conjunto esse que the permite escolher livremente o modo de vida de sua preferência. Tal como Gough dá destaque à autonomia, Sen enfatiza a liberdade, um e outro, portanto, distanciando-se de uma abordagem meramente quantitativa do entendimento do que são carências ou déficits:

Um patamar de renda pode revelar-se inadequado não porque se situa abaixo de uma linha de pobreza, fixada com base em parâmetros exógenos, mas porque está abaixo do que é adequado para mobilizar um conjunto específico de habilidades (capabilities) compatíveis com as necessidades da uma determinada pessoa. (Sen, 1992, p.111)

Somente um indivíduo autônomo será sujeito nas esferas econômica, psicológica, sociocultural e/ou política, pois é um indivíduo que interroga, reflete e delibera com liberdade e responsabilidade, ou, como diz Castoriadis (1992), "é capaz de uma atividade refletida própria e não de uma atividade que foi pensada por outro sem a sua participação". Autônomo, segundo Castoriadis (1992, p.139), é aquele que reconhece, nas leis e no poder da sociedade, suas próprias leis e seu próprio poder: "a autonomia surge, como germe, assim que a interrogação explícita e ilimitada se manifesta".

Por se estar tratando de políticas sociais, entende-se que se deve apontar para a expansão das capacidades dos indivíduos, o que fez que a equipe incorporasse a noção de autonomia como conceito-chave para analisar a efetividade de programas sociais na condição de vida das famílias atendidas, enriquecida pelas ponderações sobre liberdade, capacidade de opção e oportunidades.

\section{Dimensões de acompanhamento do sistema}

O SIGS foi desenhado para permitir desenvolver as capacidades analíticas e reflexivas dos atores envolvidos. Nesse sentido, o sistema pretende ser uma ferramenta informacional que permita ser alimentada de forma consistente com informações de qualidade - tornando a organização e seus serviços transparentes e abertos a uma construção coletiva, e possibilitando o exercício do controle social.

Para a construção do sistema, adotou-se a concepção de que indicadores são instrumentos de medição, conjunto de variáveis, medidas indiretas, que possibilitam captar e medir um conceito. Segundo Januzzi (2001), o indicador social para a pesquisa acadêmica é "o elo [...] entre os modelos explicativos da teoria social e a evidência empírica dos fenômenos sociais observados", e, para a formulação de políticas públicas, é um instrumento operacional, de monitoramento, avaliação, formulação e reformulação de políticas públicas: 
Um Indicador Social é uma medida em geral quantitativa, dotada de um significado social substantivo, usado para substituir, quantificar ou operacionalizar um conceito social abstrato, de interesse teórico (para pesquisa acadêmica) ou programático (para formulação de políticas). É um recurso metodológico, empiricamente referido, que informa algo sobre um aspecto da realidade social ou sobre mudanças que estão se processando na mesma. (Januzzi, 2002, p.54)

Busca, assim, decompor o conceito de autonomia, ou processo de autonomização, em sete dimensões analíticas, que, por meio de um conjunto de indicadores, permitam conhecer, medir e analisar os impactos do programa na vida das famílias beneficiárias. Objetiva-se captar em que medida essas famílias passaram por alterações ou não na sua qualidade de vida, após a entrada no programa. As dimensões são as seguintes:

- Condições de moradia - que compreendem as condições da unidade habitacional e a qualidade do domicílio da família e as condições básicas de infra-estrutura e qualidade ambiental da moradia.

- Acesso territorial a serviços sociais - entendidos no âmbito dos direitos de cidadania, isto é, a presença no território de equipamentos públicos e possibilidade de acesso da população aos serviços básicos: saúde, educação, cultura, lazer, segurança, assistência social. Como saúde e educação são consideradas necessidades básicas e direitos universais, e ao mesmo tempo são requisitos do programa em questão, aparecem como indicadores obrigatórios de acompanhamento. Nesses itens, busca-se capturar o acesso e a freqüência às unidades básicas de saúde, a cobertura de vacinação de crianças até cinco anos, o potencial de acesso à creche, educação infantil e ensino fundamental; o aumento na matrícula e freqüência escolar; e a diminuição do índice de evasão escolar.

- Trabalho e renda - captura mudanças no acesso a programas de qualificação profissional, geração de emprego e renda; nas possibilidades de inserção ou reinserção no mercado de trabalho e na situação de renda familiar. Paralelamente, já que o critério e perfil da população atendida pelo programa é o de baixa renda, opta-se por aferir o acesso a benefícios sociais, contributivos ou não, que complementam a renda familiar e podem contribuir para a satisfação das necessidades básicas da família.

- Condições de risco pessoal e social - como a população atendida pelos programas de transferência/complementação de renda está mais exposta a um conjunto de fatores que geram condições e situações de vulnerabilidade social, considera-se importante a observação de alguns fenômenos: violência urbana, violência doméstica, trabalho infantil, presença de crianças e adolescentes em medidas socioeducativas ou liberdade assistida e presença de pessoas com deficiência.

- Relações de gênero e geracionais-compreende o conjunto de fatores que definem maior ou menor grau de convivência, comunicação e tolerância entre os membros da família, dadas suas diferenças. 
- Auto-estima - entendida como o olhar das pessoas a respeito de si mesmas, o reconhecimento de si e a possibilidade de, a partir desse olhar, alterar as suas relações consigo mesmas e com o mundo. Essas alterações podem ser percebidas a partir da apropriação e/ou mudança de atitudes em relação à família, à comunidade, ao grupo e a si próprio.

- Participação social-como referência geral, compreende-se participação social como cidadania ativa, conquista da sociedade civil organizada no sentido da construção de espaços públicos democráticos e plurais. Temse como pressuposto que o exercício da cidadania nos espaços de sociabilidade dos programas de complementação de renda (grupos socioeducativos) e organização local (bairro/território) possibilita desenvolver a consciência dos direitos, valores, auto-estima, e as capacidades de relacionamento e comunicação, criando ainda a disposição para participar em movimentos sociais ou ações coletivas. O conceito de participação está restrito às diversas formas de relação social estabelecida pelas famílias participantes do programa, nos espaços de discussão do próprio programa (reuniões e atividades socioeducativas), como também na participação nos espaços de sociabilidade e de organização local.

A equipe do Instituto de Estudos Sociais, juntamente com seus parceiros, vem elaborando rico material sobre o Sistema de informação em Gestão Social e sobre o trabalho social com famílias vulnerabilizadas. Metodologias (de monitoramento e avaliação e de trabalho socioeduca-tivo) têm sido construídas, bem como material pedagógico para qualificação de equipes técnicas e atuação junto aos grupos socioeducativos desses.

\section{Notas}

l Construído numa parceria entre a Secretaria de Assistência Social do Município de São Paulo e o Centro de Estudos da Metrópole (CEM) do Centro Brasileiro de Análise e Planejamento (Cebrap), buscou identificar as diferentes condições de carências sociais, por meio da análise da distribuição da estrutura socioeconômica no espaço urbano disponível em: <http://www.centrodametropole.org.br>

2 Segundo Townsend (1993), "necessidades básicas incluem um requerimento mínimo por família no plano do consumo privado: alimentação adequada, vestuário, bem como alguns móveis e equipamentos para o domićlio. Em segundo lugar, inclui serviços essenciais ofertados para e pela comunidade num sentido amplo, tais como água potável, saneamento, transporte público, saúde, educação e serviços culturais [...] O conceito de necessidades básicas deve se inscrever no contexto do grau de desenvolvimento econômico e social da nação como um todo".

3 Entre outros, consultar: Wanderley (1999 e 2004), Wanderley (2000), Telles (2001), Benevides (1991), Covre (1991), Sawaia (2001).

$4 \mathrm{E}$ os meios para funcionar tratam do ser e do fazer, ou seja, do que se refere ao que se é, bem como da capacidade de agir, de fazer acontecer. 
Referências bibliográficas

BARTHES, R. Mythologies. Paris: Seuil, 1957. (Coll. "Points").

BENEVIDES, M. V. M. A cidadania ativa: referendo, plebiscito e iniciativa popular. São Paulo: Ática, 1991.

BOURDIEU, P. La distinction. Paris: Minuit, 1979.

BRAGA, V. Cultura alimentar: contribuição da antropologia da alimentação, Piracicaba. Saúde Revista, v.6, n.13, p.37-44, 2004. Disponível em: <http://www.unimep.br/ phpg/editora/revistaspdf/saudel3art05.pdf>.

BRASIL É O PAIS do arroz com feijão. Folha de S.Paulo, São Paulo, 26 de junho 2005.

CASTORIADIS, C. O mundo fragmentado. Trad. Rosa Maria Boaventura. Rio de Janeiro: Paz e Terra, 1992. v.3: As encruzilhadas do labirinto.

COVRE, M. L. M. O que é cidadania? São Paulo: Brasiliense, 1991.

DANNER, D. D. et al. Positive emotions in early life and longevity: findings from the Nun Study. Journal of Personality and Social Psychology, v.80, p.804-13, 2001.

DOYAL, L.; GOUGH, I. A Theory of Human Need. New York: The Guilford Press, 1991.

FRANKL, V. E. A questão do sentido em psicoterapia. Campinas: Papirus, 1990.

FREDRICKSON, B. L.; LEVENSON, R. W. Positive emotions speed recovery from the cardiovascular sequelae of negative emotions. Cognition and Emotion, v.12, p.191$220,1998$.

GIUSSANI, L. O senso religioso. São Paulo: Nova Fronteira, 2000.

GOUGH, I. Global Capital, Human Needs and Social Policies. Selected Essays, 2000: 1994-99.

JANUZZI, M. Indicadores sociais no Brasil. Conceitos, fontes de dados e aplicações. Campinas: Alinea, 2001.

Repensando a prática de uso de indicadores sociais na formulação e avaliação de políticas públicas municipais. In:__. Qualidade de vida: observatórios, experiências e metodologias. São Paulo: Anablume, Fapesp, 2002. p.53-71.

KOGA, D. Território e políticas públicas. In: WANDERLEY, M. B.; OLIVEIRA, I. M. C. (Org.) Trabalhando com famílias. São Paulo: IEE-PUCSP, 2004.

LAVINAS, L. Rede Urbal: Documento Base URB-AL 10. REDE URBAL 10 Luta Contra a Pobreza Urbana, Documento de Guia. In: Rede Urbal. São Paulo: PSP/Sec. Rel. Internacionais, texto, 2003.

LEEUW, G. Fenomenologia della religione. Torino: Paolo Boringhieri, 1960.

LEVI-STRAUSS, C. Le triangle culinaire. Aix en Provence: L'Arc, 1965.

MACIE, L. M. E.; MENASCHE, R. Alimentação e cultura, identidade e cidadania. O Brasil tem fome de quê? Disponível em: $<$ http://brazil-brasil.com/index.php?option= content\&task=view\&id $=228>$.

MARX, K. Manuscritos econômicos e filosóficos. Terceiro manuscrito. In: Os pensadores. São Paulo: Abril Cultural, 1978.

MATTA, R da. O que faz o Brasil, Brasil? Rio de Janeiro: Rocco, 1986. 
MONTEIRO, C. A. A dimensão da pobreza, da desnutrição e da fome no Brasil. Estudos Avançados, São Paulo, v.17, n.48, maio-ago. 2003.

NARAYAN, D. et al. Can anyone hear us? Voices of the Poor. New York: Oxford University Press, 2000.

O ESTADO DE S. PAULO. Na sala de aulas de São Paulo, 25\% estão desnutridos e obesos. O Estado de S. Paulo, São Paulo, 22.5.2005.

PEREIRA, A. P. Necessidades humanas: subsídios à critica dos mínimos sociais. São Paulo: Cortez, 2000.

PETERSON, C. et al. Pessimistic explanatory style is a risk factor for physical illness: A thirty-five year longitudinal study. Journal of Personality and Social Psychology, v.55, p.23-7, 1988.

SAWAIA, B. Participação social e subjetividade. In: SORRENTINO, M. (Coord.) Ambientalismo e participação na contemporaneidade. São Paulo: Educ/Fapesp, 2001.

SAWAYA, A. L. et al. Os dois Brasis: quem são, onde estão e como vivem os pobres brasileiros. Estudos Avançados, São Paulo, v.17, n.48, maio-ago. 2003.

SEN, A. Poverty and Affluence. In: Inequality Reexamined. New York: Russell Sage Foundation, 1992.

. Desenvolvimento com liberdade. São Paulo: Companhia das Letras, 2000.

SOLYMOS, G. M. B. A experiência vivida de mães de desnutridos: um novo enfoque para intervenção em desnutrição infantil. In: SAWAYA, A. L. (Org.) Desnutrição urbana no Brasil em um período de transição. São Paulo: Cortez, 1997.

Estudo corte transversal e qualitativo de manifestações psicopatoló-gicas não específicas em Vila Mariana, Município de São Paulo. São Paulo, 2000. Tese (Doutorado) - Escola Paulista de Medicina, Universidade Federal de São Paulo.

TELLES, V. S. Sociedade Civil e construção de espaços públicos. In: DAGNINO, E. (Org.) Anos 90: politica e sociedade no Brasil. São Paulo: Brasiliense, 1994.

Pobreza e cidadania. São Paulo: USP, Editora 34, 2001.

TOWNSEND, P. Conceptualising Poverty. In: The International Analysis of Poverty. London: Harvester Wheatsheaf, 1993.

WANDERLEY, L. E. Educação para a cidadania. Revista Serviço Social e Sociedade, São Paulo, n.62, 2000.

WANDERLEY, M. B. As questões da exclusão social. In: SAWAIA, B. (Org.) As artimanhas da exclusão - análise e estica da desigualdade social. Petrópolis: Vozes, 1999.

WANDERLEY, M. B. et al. (Org.) Desigualdade e questão social. 2.ed. revisada e ampliada. São Paulo: Educ, 2004.

WANDERLEY, M. B. e OLIVEIRA, I. M. C. (Orgs.) Trabalho com famílias. Metodologia e monitoramento (v.1) e Textos de apoio (v.2). São Paulo: IEE-PUC-SP, 2004.

RESUMO - NOSSO OBJETIVO neste texto é apresentar a trajetória teórico-metodológica vivida pela equipe de pesquisadores do Instituto de Estudos Especiais (IEE-PUC/SP) na construção do Sistema Informacional de Gestão Social (SIGS) - que permite efetuar a gestão de programas sociais voltados para famílias em situação de vulnerabilidade social. 
Demos destaque aos conceitos pilares dessa construção: pobreza/desigualdade social; território; necessidades e vulnerabilidades sociais; autonomização.

PALAVRAS-CHAVE: Pobreza, Autonomia, Liberdade, Gestão social.

ABSTRACT - OUR GOAL in this text is to present the theoretical/methodological path followed by the team of researchers from the Institute of Special Studies (IEE-PUC/ SP), who built the Social Management Information System (SIGS) to help manage social programs for socially vulnerable families. Special emphasis is given to the conceptual pillars of their construction: poverty/social inequality; territory; social needs and vulnerabilities; "autonomization".

KErWORDS: Poverty and social inequalities, Autonomy, Liberty, Social Management.

Mariangela Belfiore Wanderley é professora associada do Departamento de Metodologia da Faculdade de Serviço Social, coordenadora do Programa de Pós-Graduação em Serviço Social, e diretora do Instituto de Estudos Especiais da PUC-SP.

O conteúdo do artigo é fruto do trabalho coletivo do Núcleo SIGS e pesquisadores do IEE da PUC-SP.

Recebido em 16.1.2006 e aceito em 27.1.2006. 